\title{
Investigation of Natural Plasticizers in Concrete
}

\author{
Dr. Ravindra $\mathbf{R}^{1}$, Dr. Raviraj A Kusanur ${ }^{2}$ and Aravind Sajjanar ${ }^{3}$
}

Abstract- Use of plasticizers to reduce the water content in concrete has been the emerging technology. Many chemically synthesized plasticizers are in use. This article mainly presents on rain tree (Albizia saman) pod extract used as plasticizer. The extraction of solution from rain tree pod is done by crushing and soaking of pods in water and fermented to remove sugars responsible for retardation. These solutions are added to concrete in various dosages. Workability tests and compressive strength tests are conducted on normal concrete and concrete to which natural plasticizer is added. Durability test is also conducted on concrete cubes. The results showed that all solutions extracted from the rain tree pod improved workability and gives water reduction of about $10 \%$. On adding the rain tree pod extract at $10 \%$ dosage an increase of $12.77 \%$ compressive strength is achieved. Concrete also exhibited good workability and durability. The authors have patented the use of Rain tree pod extract as plasticizer.

Keywords - plasticizer, rain tree pod, workability, compressive strength.

\section{INTRODUCTION}

Admixtures used to increase the plasticity or workability in fresh state of concrete are called plasticizers or water reducers [1]. Based on the degree to which it increases the workability, it can be classified as plasticizers $(5-10 \%$ water reduction) or super plasticizers $(12-30 \%$ water reduction)[2]. Water reduction due to plasticizers is accompanied by an increase in compressive strength $(10-25 \%)$.

Plasticizers indirectly gives strength to hardened concrete by improving workability of a concrete mix at the time of its mixing and placing thereby allowing decrease in water-cement ratio. Decrease in water cement ratio improves the strength of concrete. Normally when Plasticizers in dosage of $0.1 \%$ to $0.5 \%$ by amount of cement are added, the decrease in water content for a certain degree of workability will be in the range of $5 \%$ to $15 \%$.Lot of research has been done to improve the workability by using natural plasticizers.

Shobha M. S.[3] examined on the addition of natural rubber latex into the Metakaoline blended concrete to increase the performance of the normal concrete. The study concludes with the optimum dosage of natural rubber latex to be $1 \%$ by weight of cement in the concrete.

Otoko G. R. et al.[4] investigated on usage of palm liquor as concrete admixture and set retarder. The results obtained shows that palm liquor shows improvement in honey combing, compaction and increases the workability of concrete with maximum performance at replacement of $16 \%$ water by palm liquor.

Magendran Subramani[5] studied on effects of addition of palm oil fiber on density, workability, compressive and flexural strength of concrete. On addition of palm oil fibers at $0.5 \%$

\footnotetext{
${ }^{1}$ Department of Civil Engineering R. V. College of Engineering, Bengaluru, Karnataka, India

2 Department of Chemistry R. V. College of Engineering, Bengaluru, Karnataka, India

${ }^{3}$ Department of Civil Engineering R. V. College of Engineering, Bengaluru, Karnataka, India
} 
of cement to concrete, an increase in the flexural and compressive strength was observed.

Abdeljaleel N. S. et al.[6] used cleanest kind of gum arabic, which is extracted from (Hashab) trees. Gum arabic liquid is used to concrete mixes at various proportions with respect to cement content. Addition of gum arabic at $0.4 \%$ of cement content to the concrete mixes has showed improvement in compressive strength.

Rain trees (Albizia saman) are abundantly found in the tropical regions. The pod of this tree is generally considered a waste material in our country. An attempt on optimized extract of rain tree pod as plasticizer is made in concrete and checked for workability, compressive strength and durability.

\section{METHODOLOGY}

Rain tree pod solution is prepared by crushing the rain tree pod after the seeds are removed. The crushed rain tree pods are soaked in water for seven days. Rain tree pod has high amount of carbohydrates which affects the setting time of concrete. The solution is fermented by adding small quantity of yeast. The optimum dosage of the fermented extract solution as plasticizer in concrete is found out by marsh cone test.

Preliminary tests are conducted on cement, fine aggregate and coarse aggregate like fineness modulus, specific gravity, water absorption, initial and final setting time of cement, consistency of cement paste.

Design mix of M20 grade concrete is designed as per IS 10262:2009[7]. Different workability tests are conducted to study the effect of plasticizers added at different dosages. Proportion of materials are mixed according to design mix, cast in solid concrete cubes of $150 \mathrm{~mm} \mathrm{X} 150 \mathrm{~mm} \mathrm{X}$ $150 \mathrm{~mm}$ size and then cured for 28 days. The cured concrete blocks are tested for compressive strength, water absorption and durability. Durability test is carried out by considering alternative wetting and drying process for 7 cycles (14 days).

\section{EXPERIMENTAL INVESTIGATION}

\subsection{Materials}

Various tests on cement, fine aggregates and coarse aggregates are as follows.

\section{Cement}

Ordinary Portland Cement 53 Grade confirming to IS 12269:1987[8] cement is used for work undertaken are shown in Table 3.1.

Table 3.1: Properties of Cement

\begin{tabular}{|c|c|}
\hline Properties & Values \\
\hline $\begin{array}{c}\text { Normal } \\
\text { Consistency }\end{array}$ & $30 \%$ \\
\hline Specific Gravity & 3.13 \\
\hline $\begin{array}{c}\text { Initial setting } \\
\text { time }\end{array}$ & $148 \mathrm{~min}$ \\
\hline Final setting time & $436 \mathrm{~min}$ \\
\hline
\end{tabular}

\section{Coarse aggregates}

$20 \mathrm{~mm}$ down size coarse aggregates are used for work undertaken and tabulated in Table 3.2.

Table 3.2: Properties of coarse aggregates

\begin{tabular}{|l|l|}
\hline Tests & Values \\
\hline
\end{tabular}




\begin{tabular}{|c|c|}
\hline Specific gravity & 2.7 \\
\hline Water absorption & $0.42 \%$ \\
\hline
\end{tabular}

Fine aggregates

Dried Fine aggregates passing through $4.75 \mathrm{~mm}$ sieve are used in concrete. The properties of fine aggregates are tabulated in Table 3.3. Particle size distribution of sand is shown in Fig. 3.1.

Table 3.3: Properties of fine aggregates

\begin{tabular}{|c|c|c|c|c|c|}
\hline Type of concrete & $\begin{array}{c}\text { W/C } \\
\text { ratio }\end{array}$ & $\begin{array}{c}\text { Dosage } \\
(\%)\end{array}$ & Slump & Flow (\%) & $\begin{array}{c}\text { Compaction } \\
\text { factor }\end{array}$ \\
\hline
\end{tabular}

\begin{tabular}{|c|c|}
\hline Properties & Values \\
\hline Fineness modulus & 2.31 \\
\hline Zone (IS & III \\
383:1970)[9] & \\
\hline
\end{tabular}

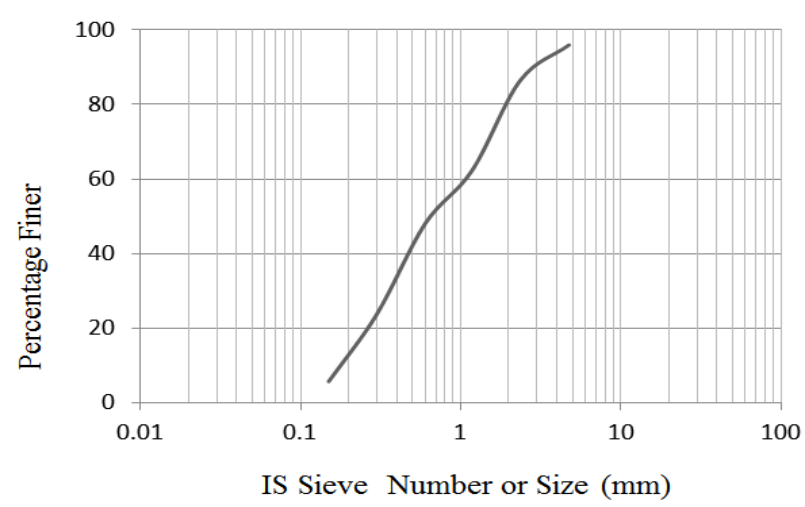

Fig. 3.1: Particle size distribution curve

\subsection{Preparation of natural plasticizer sample}

Fully ripened rain tree pods are collected, crushed into pieces and seeds are removed. The crushed pieces are soaked in water for 14 days. The solution is then filtered. In order to increase the concentration of extract, a part of extract was boiled. Extracts of rain tree pod which are unboiled and boiled are subjected to fermentation for 7 days by adding yeast. The fermented extracts are used as plasticizer.

The specific gravity and concentration of extracts are shown in Table 3.4.

Table 3.4: Properties of rain tree pod solution

\begin{tabular}{|c|c|c|}
\hline Type of solution & Specific gravity & Concentration ( gm/lt ) \\
\hline $\begin{array}{c}\text { Unboiled } \\
\text { solution }\end{array}$ & 1.0148 & 14.81 \\
\hline Boiled solution & 1.022 & 22.22 \\
\hline
\end{tabular}




\begin{tabular}{|c|c|c|c|c|c|}
\hline Normal concrete & 0.55 & 0 & 72 & 60 & 0.862 \\
\hline $\begin{array}{c}\text { With unboiled and } \\
\text { fermented } \\
\text { plasticizer }\end{array}$ & 0.5 & 0.1 & 87 & 92 & 0.935 \\
\cline { 3 - 6 } & 0.2 & 75 & 84 & 0.908 \\
\hline $\begin{array}{c}\text { With boiled and } \\
\text { fermented } \\
\text { plasticizer }\end{array}$ & 0.5 & 0.2 & 35 & 92 & 0.917 \\
\cline { 3 - 6 } & & & 63 & 96 & 0.923 \\
\hline
\end{tabular}

\section{Qualitative test for rain tree pod extract}

Chemical tests like Osazone and Tollen's reagent tests are done to confirm presence of sugars in rain tree pod extract. These tests are conducted for both unboiled and boiled samples.

In Osazone test, the unboiled or boiled extract was treated with Phenyl hydrazine. The yellow precipitate of Osazone is formed which indicates the presence of sugar in the extract. The same test was performed for fermented extract, there was no formation of yellow precipitate, which indicates absence of sugar.

Similarly in Tollen's reagent test, sample gives black precipitate for the unboiled or boiled extract. This indicates the presence of sugar in the extract. The same test was performed after fermentation; there is no formation of black precipitate, which indicates absence of sugar.

\subsection{Optimum Dosage of Plasticizer}

Marsh Cone Experiment corresponding to ASTM D6910-04 is conducted to determine optimum dosage for both unboiled and boiled plasticizers

Optimum dosage for both unboiled plasticizer and boiled plasticizer is $0.1 \%$ as shown in Fig 3.2 .

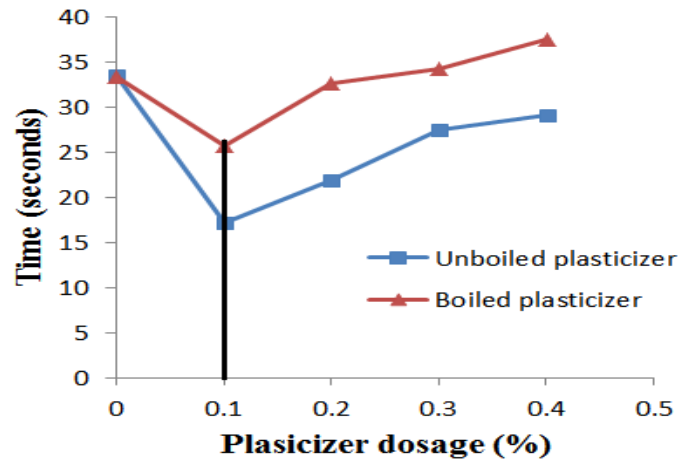

Fig 3.2: Optimum dosage for unboiled and boiled plasticizer

\subsection{Mix proportion}

Mix proportion is made according to IS 10262-2009[7] to achieve a characteristic strength of $20 \mathrm{~N} / \mathrm{mm}^{2}$. The mix proportion of cement, fine aggregates and coarse aggregates is found to be (1: 1.8: 3.3).

\subsection{Workability of concrete}

Design mix of fresh concrete is checked for slump, compaction factor and flow test. Table 3.5 gives results for various workability tests; slump test, flow test and compaction factor test.

Table 3.5: Workability test results 


\subsection{Casting of specimen}

Cubes are cast in moulds of $150 \mathrm{~mm}$ X $150 \mathrm{~mm}$ X $150 \mathrm{~mm}$ size. These are demoulded after 24 hours and cured for 28 days by immersing in water.

\subsection{Compression Test}

Concrete cured for 7 and 28 days for compression strength and results shown in Table 3.6.

Table 3.6: Compressive strength results

\begin{tabular}{|c|c|c|c|c|}
\hline \multirow[t]{2}{*}{ Cube type } & \multirow{2}{*}{$\begin{array}{l}\mathrm{W} / \mathrm{C} \\
\text { ratio }\end{array}$} & \multirow{2}{*}{$\begin{array}{l}\text { Plasticizer dosage } \\
\qquad(\%)\end{array}$} & \multicolumn{2}{|c|}{$\begin{array}{c}\text { Compressive strength } \\
(\mathrm{MPa})\end{array}$} \\
\hline & & & 7 days & 28 days \\
\hline Normal concrete & 0.55 & 0 & 15.44 & 25.45 \\
\hline Boiled and fermented & 0.5 & 0.1 & 17.01 & 28.67 \\
\hline \multirow{2}{*}{ Boiled and fermented } & \multirow{2}{*}{0.5} & 0.1 & 17.01 & 28.67 \\
\hline & & 0.2 & 14.05 & 26.95 \\
\hline \multirow{2}{*}{ Unboiled and fermented } & \multirow{2}{*}{0.5} & 0.1 & 16.21 & 28.7 \\
\hline & & 0.2 & 13.99 & 27.45 \\
\hline
\end{tabular}

\subsection{Durability of concrete blocks by alternative wetting and drying}

The resistance to climatic condition of concrete blocks is simulated by subjecting to repetitive alternate wetting and drying. Durability depends upon volumetric changes due to moisture movements in the surroundings. If there is excessive volume change due to alternate wetting and drying, the bond in concrete is liable to be destroyed, causing cracks to appear in the hard set mortar. Alternate wetting and drying process is carried out for 7 cycles. No cracks in surface or deterioration are observed after 7 cycles.

\subsection{Water absorption test}

In the present study the amount of water absorbed when immersed in water and the loss in weight of the cube are noted. After 24 hours of immersion in water wet specimen's weight is noted down and then place in oven for the duration of 24 hours at a temperature of $110 \pm 5{ }^{\circ} \mathrm{C}$. After 24 hours, the specimen is taking out from the oven and dry weight of specimen noted. The variation in the weights will provide the amount of the capacity of the water absorption of the cube.

\section{RESULTS AND DISCUSSIONS}

The results of the various tests performed are as follows.

\subsection{Optimum dosage}

Optimum dosage of each type extract by marsh cone test is $0.1 \%$.

\subsection{Compressive strength}

Fig. 4.1 shows variation of compressive stress of concrete block for both with and without plasticizer.

Compression test result shows that compressive strength of specimens with plasticizer added at $0.1 \%$ dosage is more when compared to specimens without plasticizer. Concrete cubes which are cured for 7 days are found to atleast more than $2 / 3$ rd of 28 day compressive strength. 


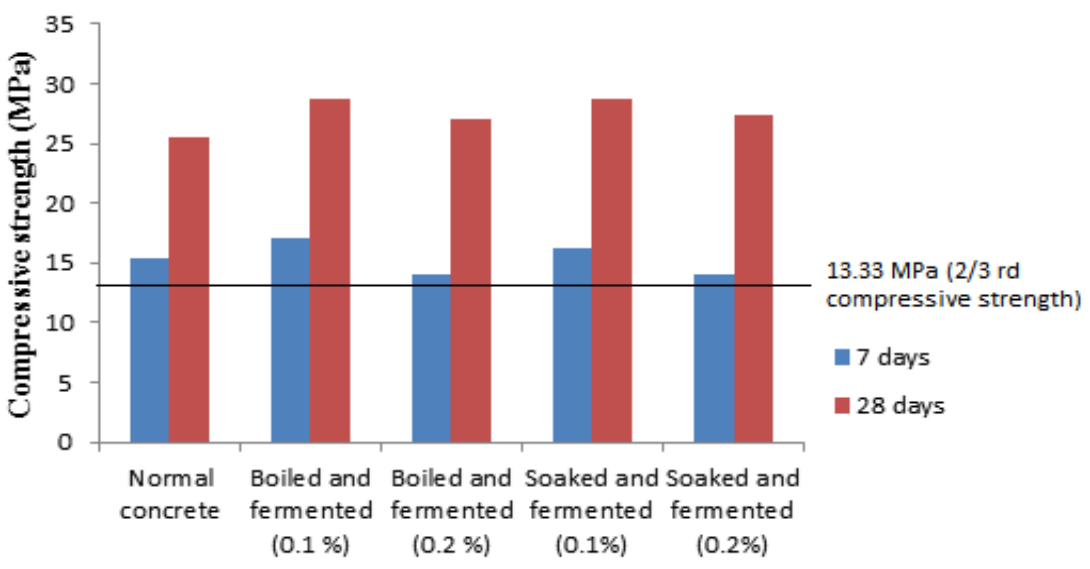

Fig. 4.1: Variation of compressive strength.

\subsection{Water absorption test}

Table 4.1 shows the test result of water absorption for concrete blocks cast and cured with and without plasticizer. Water absorption is calculated in the first cycle of the durability test.

Table 4.1: Water absorption test results

\begin{tabular}{|c|c|c|}
\hline $\begin{array}{c}\text { Type of } \\
\text { concrete }\end{array}$ & Dosage (\%) & $\begin{array}{c}\text { Avg. Water absorption } \\
(\%)\end{array}$ \\
\hline $\begin{array}{c}\text { Normal } \\
\text { concrete }\end{array}$ & 0 & 4.81 \\
\hline $\begin{array}{c}\text { Unboiled and } \\
\text { fermented }\end{array}$ & 0.1 & 4.45 \\
\cline { 2 - 3 } & 0.2 & 4.28 \\
\hline $\begin{array}{c}\text { Boiled and } \\
\text { fermented }\end{array}$ & 0.1 & 4.23 \\
\cline { 2 - 3 } & 0.2 & 3.89 \\
\hline
\end{tabular}

The observations made during the study of water absorption test are:

1. Water absorption of all type of concrete specimens are within the permissible limit specified by ASTM C 140. i.e. less than 5\%.

2. Water absorption of concrete specimen with plasticizer is found to be lesser than normal concrete.

3. For unboiled and fermented specimens water absorption is more than boiled and fermented specimens.

4. As dosage of plasticizer increases the water absorption decreases.

\section{CONCLUSIONS}

The conclusion of the research work undertaken as follows.

1. Optimum dosage for unboiled and boiled solution used as plasticizer in different trials of concrete cube casting is found to be $0.1 \%$.

2. The Osazone and Tollen's reagent test of carbohydrates performed on extract of rain tree pod confirms the absence of glucose, fructose and sucrose in fermented solutions.

3. Both fermented boiled and unboiled solution have significantly less retarding effect on concrete when compared to unfermented solutions.

4. The fermented boiled and unboiled solution inhibits good workability, increased hardening rate and increase in compressive strength compare to normal concrete. 
5. The average water content reduction can be made up to $10 \%$ when rain tree pod extract plasticizer used.

6. Compared to normal concrete of design mix (1: 1.8: 3.3) (M20 grade) percentage increase in compressive strength of concrete to which plasticizer added, at end of 28 days is as follows:

- For boiled and fermented solution concrete compressive strength increased by $12.65 \%$ for $0.1 \%$ dosage.

- For soaked and fermented solution concrete compressive strength increased by $12.77 \%$ for $0.1 \%$ dosage.

7. No retardation effect was obtained on using Rain tree pod solution as plasticizer.

8. Compared to plasticizers which are available in market, rain tree pod plasticizer is economical and eco-friendly.

\section{ACKNOWLEDGEMENT}

The authors acknowledge Department of Civil Engineering R. V. College of Engineering, Bengaluru for providing the laboratory infrastructure required to conduct the research work.

\section{REFERENCES}

[1] Bedard, C, P, E., and Mailvaganam, N, P., "The Use of Chemical Admixtures in Concrete", ASCE Journal of Performance of Constructed Facilities, Vol 23, 2005, pp 263-266.

[2] Grabiec, A, M., "Contribution to the knowledge of superplasticizer effect on some characteristics of concrete after long periods of hardening", Cement and Concrete ResearchElsevier, Vol 29, 1999, pp 699-704.

[3] Shobha, M, S., "Mechanical Properties of Latex Modified High Performance Concrete", IOSR Journal of Mechanical and Civil Engineering (IOSR-JMCE), Vol 11, 2014, pp 13-19.

[4] Otoko, G, R., and Ephraim, M, E., "Concrete and Set Retarder potential of Palm Liquor", European International Journal of Science and Technology, Vol 21, 2014, pp 168-174.

[5] Magendran, Subramani., "Palm oil fibre as an additive in concrete", Doctoral thesis, University Teknologi Malaysia, 2007.

[6] Abdeljaleel, N, S., Hassaballa, A, E., Rahman, A., Mohamed, E., "The Use of Gum Arabic Liquid and Modified Liquid in Concrete Mixes", Innovative Systems Design and Engineering, Vol 3, 2012, pp 1654-1660.

[7] IS 10262, Concrete Mix Proportioning Guidelines. Indian Stadard, 2009.

[8] IS11269, 53 grade ordinary Portland cement, Indian Standards, 1987.

[9] IS 383, Specification for coarse and fine aggregates from natural sources for concrete, Indian Standards, 1970. 